\title{
EDITORIAL
}

\section{Medical therapy for COPD: lessons from the real world}

\author{
P.M.A. Calverley
}

Few people would deny that chronic obstructive pulmonary (COPD) is a major cause of mortality globally and is likely to increase in importance $[1,2]$. Although the very varied quality of community prevalence data have to be relied upon to draw these conclusions, the use of randomised controlled trials to evaluate the efficacy of treatment for COPD is more reliable. This approach has now yielded a large body of scientific data, which confirm that long-acting $\beta$-agonists (LABA) improve lung function and health status in stable COPD [3-5] whilst also increasing the time between exacerbations [4, 6]. Likewise, largescale 3-yr randomised studies have failed to find any effect of inhaled corticosteroids on the rate of decline of the forced expiratory volume in one second (FEV1), but in more severe patients, these drugs reduce the number of exacerbations [7-10]. Two large 1-yr studies have shown that combining these treatments reduces further symptomatic improvements and larger pulmonary function changes than either alone. These studies have thus far only been presented at scientific meetings but have been submitted for publication.

Data based on randomised controlled trials have many advantages but there are some disadvantages to be considered. Patients who enter these studies, especially the larger ones (1-3 yrs), have to be motivated, compliant with treatment and clinically stable in the weeks or even months before they enter the trial. They must meet the arbitrary bronchodilator reversibility criteria often imposed by the trial design, which may not be representative of the degree of responsiveness seen in unselected patients. In addition, they must not be limited in their comorbidity and/or require any class of treatment, which could conflict with that chosen for the clinical investigation. Unsurprisingly, such patients tend to be rather "atypical" in comparison with those seen in normal clinical practice and evaluating the size of any treatment benefit is difficult.

An alternative approach is to use the increasing amount of information retained in patient databases and to observe the relationship between the actual treatment used and relevant outcomes. This offers access to a large number of unselected patients and uses powerful statistical methods to control for potential confounding variables. The Canadian healthcare system appears particularly suited to this type of

Correspondence: P.M.A. Calverley, Clinical Science Centre, University Hospital Aintree, Longmoor Lane, Liverpool, UK. Fax: 44 1515295888. E-mail: pmacal@liverpool.ac.uk analysis and has already contributed useful data about the risks of $\beta$-agonist treatment in asthma [11]. More recently, data from Ontario, Canada, has shown that elderly patients prescribed inhaled corticosteroids within 30 days of discharge after an acute exacerbation of COPD were $26 \%$ less likely to be hospitalised in the succeeding year than in those in whom this treatment was not selected, a finding that appeared robust when stratified for patient sex and comorbidity [12]. These data have now been extended in a different healthcare system, which has provided an even more comprehensive set of clinical information.

In this issue of the journal, SorIANo et al. [13] report their analysis of a cohort of patients aged $>50 \mathrm{yrs}$ and with a diagnosis of COPD identified from the British General Practice Research Database, a validated clinical data set derived from general practitioners serving $\sim 1$ million patients within the UK. These patients had their smoking status and treatment use recorded, which was a significant advantage compared to the data from Ontario. The authors compared patients who had been prescribed the inhaled corticosteroid fluticasone and the LABA salmeterol, together with those who had received either alone and a larger "control" group in which neither drug had been prescribed. After a 6-month run-in period to exclude those patients who died and confirm treatment exposure, they followed the patients' progress as documented in the case records for a further 3 yrs. They found that prescription of inhaled corticosteroids and a LABA produced a significant reduction in the relative risk of death, a finding also seen in those receiving only inhaled corticosteroids and with a trend to improved survival in the LABA only group. When they extended their analysis to include data about all the available inhaled corticosteroids and not just fluticasone they confirmed their initial observations. These data have several internally consistent features. Mortality rose in the population significantly as age increased and the presence of increasing levels of comorbidity was associated with an appropriately graded increase in risk of death. Both these variables were controlled for in the relevant therapy groups.

Despite these striking findings, observational studies of this type have definite limitations that include assignment bias to the treatment of interest and recall bias when patients are asked about specific events. These problems have been clearly described elsewhere [14]. In this study, only the drug salmeterol was considered as a specimen LABA, reflecting its dominant 
prescription among COPD patients in the UK. More importantly there is significant potential for the mislabelling of patients, although SoRIANo et al. [13] have tried to address this by confirming the diagnosis of a subset of patients sent a questionnaire survey and by separately analysing any patient in whom there was ever a mention of bronchial asthma in the case record or those who had used regular oral corticosteroids. This did not modify their conclusions. A subtler variant on the same problem is that of confounding by indication, a bias that arises because the doctor prescribing the treatment makes the decision to give that drug because of a specific clinical factor present in one case but not another. This will always leave a reasonable doubt that the data are not a true reflection of the effect of treatment, which instead becomes an indirect marker of disease severity. Similarly, the lack of spirometry data to confirm both the diagnosis and assess disease severity prevents a definite conclusion being established. It is possible but not probable that those not receiving either LABA or inhaled corticosteroids had worse disease spirometrically and this explained their subsequent poor mortality. Such doubts prevent reports like that of SORIANO et al. [13] providing a definitive answer to questions about the impact of drug treatment on mortality in COPD.

What these studies really do is generate testable hypotheses for future clinical trials. In this case, the data of both Sin and Tu [12] and Soriano et al. [13] provide the logical basis for the ongoing Towards a Revolution in COPD Health (TORCH) Study, a multicentre international trial examining the relationships between inhaled long-acting $\beta$-agonists and inhaled corticosteroids given to chronic obstructive pulmonary disease patients, either singularly or together. Recruitment for this study is already advanced and $>5,000$ participants have been enrolled. Hopefully, this will resolve whether more intensive medical treatment, which improves symptoms, can also change the natural history of chronic obstructive pulmonary disease. It appears that primary care physicians are doing a better job than academics have suspected in selecting the most appropriate treatment for their patients with chronic obstructive pulmonary disease.

\section{References}

1. Murray CJ, Lopez AD. Global mortality, disability, and the contribution of risk factors: Global Burden of Disease Study. Lancet 1997; 349: 1436-1442.

2. Murray CJ, Lopez AD. Alternative projections of mortality and disability by cause 1990-2020: Global Burden of Disease Study. Lancet 1997; 349: 1498 1504.

3. Boyd G, Morice AH, Pounsford JC, Siebert M, Peslis N, Crawford C. An evaluation of salmeterol in the treatment of chronic obstructive pulmonary disease (COPD). Eur Respir J 1997; 10: 815-821.[published erratum appears in Eur Respir $J$ 1997; 10(7):].

4. Mahler DA, Donohue JF, Barbee RA, et al. Efficacy of salmeterol xinafoate in the treatment of COPD. Chest 1999; 115: 957-965.

5. Dahl R, Greefhorst LA, Nowak D, et al. Inhaled formoterol dry powder versus ipratropium bromide in chronic obstructive pulmonary disease. Am J Respir Crit Care Med 2001; 164: 778-784.

6. Rennard SI, Anderson W, ZuWallack R, et al. Use of a long-acting inhaled beta2-adrenergic agonist, salmeterol xinafoate, in patients with chronic obstructive pulmonary disease. Am J Respir Crit Care Med 2001; 163: 1087-1092.

7. Vestbo J, Sorensen T, Lange P, Brix A, Torre P, Viskum K. Long-term effect of inhaled budesonide in mild and moderate chronic obstructive pulmonary disease: a randomised controlled trial. Lancet 1999; 353: 1819-1823.

8. Pauwels RA, Lofdahl C-G, Laitinen LA, et al. Longterm treatment with inhaled budesonide in persons with mild chronic obstructive pulmonary disease who continue smoking. New Engl J Med 1999; 340: 19481953.

9. Burge PS, Calverley PM, Jones PW, Spencer S, Anderson JA, Maslen TK. Randomised, double blind, placebo controlled study of fluticasone propionate in patients with moderate to severe chronic obstructive pulmonary disease: the ISOLDE trial. BMJ 2000; 320: 1297-1303.

10. The Lung Health Study Research Group. Effect of inhaled triamcinolone on the decline in pulmonary function in chronic obstructive pulmonary disease. New Engl J Med 2000; 343: 1902-1909.

11. Spitzer WO, Suissa S, Ernst P, et al. The use of betaagonists and the risk of death and near death from asthma. New Engl J Med 1992; 326: 501-506.

12. Sin DD, Tu JV. Inhaled corticosteroids and the risk of mortality and readmission in elderly patients with chronic obstructive pulmonary disease. Am J Respir Crit Care Med 2001; 164: 580-584.

13. Soriano JB, Vestbo J, Pride NB, Kiri V, Maden C, Maier WC. Survival in COPD patients after regular use of fluticasone propionate and salmeterol in general practice. Eur Respir J 2002; 20: 819-825.

14. Vestbo J. Another piece of the inhaled corticosteroidsin-COPD puzzle. Am J Respir Crit Care Med 2001; 164: 514-515. 